\title{
LA-UR-19-30446
}

Approved for public release; distribution is unlimited.

Title:

Author(s):

Intended for:

Issued:
Fall 2019 Dissertation Update

Remedes, Tyler Joseph

Update presentation for work group

2019-10-15 
Disclaimer:

Los Alamos National Laboratory, an affirmative action/equal opportunity employer, is operated by Triad National Security, LLC for the National Nuclear Security Administration of U.S. Department of Energy under contract 89233218CNA000001. By approving this article, the publisher recognizes that the U.S. Government retains nonexclusive, royalty-free license to publish or reproduce the published form of this contribution, or to allow others to do so, for U.S. Government purposes. Los Alamos National Laboratory requests that the publisher identify this article as work performed under the auspices of the U.S. Department of Energy. Los Alamos National Laboratory strongly supports academic freedom and a researcher's right to publish; as an institution, however, the Laboratory does not endorse the viewpoint of a publication or guarantee its technical correctness. 


\section{Fall 2019 Dissertation Update}

Tyler J. Remedes

22 Oct 2019

- Los Alamos

NATIONAL LABORATORY 


\section{Summary of Presentation}

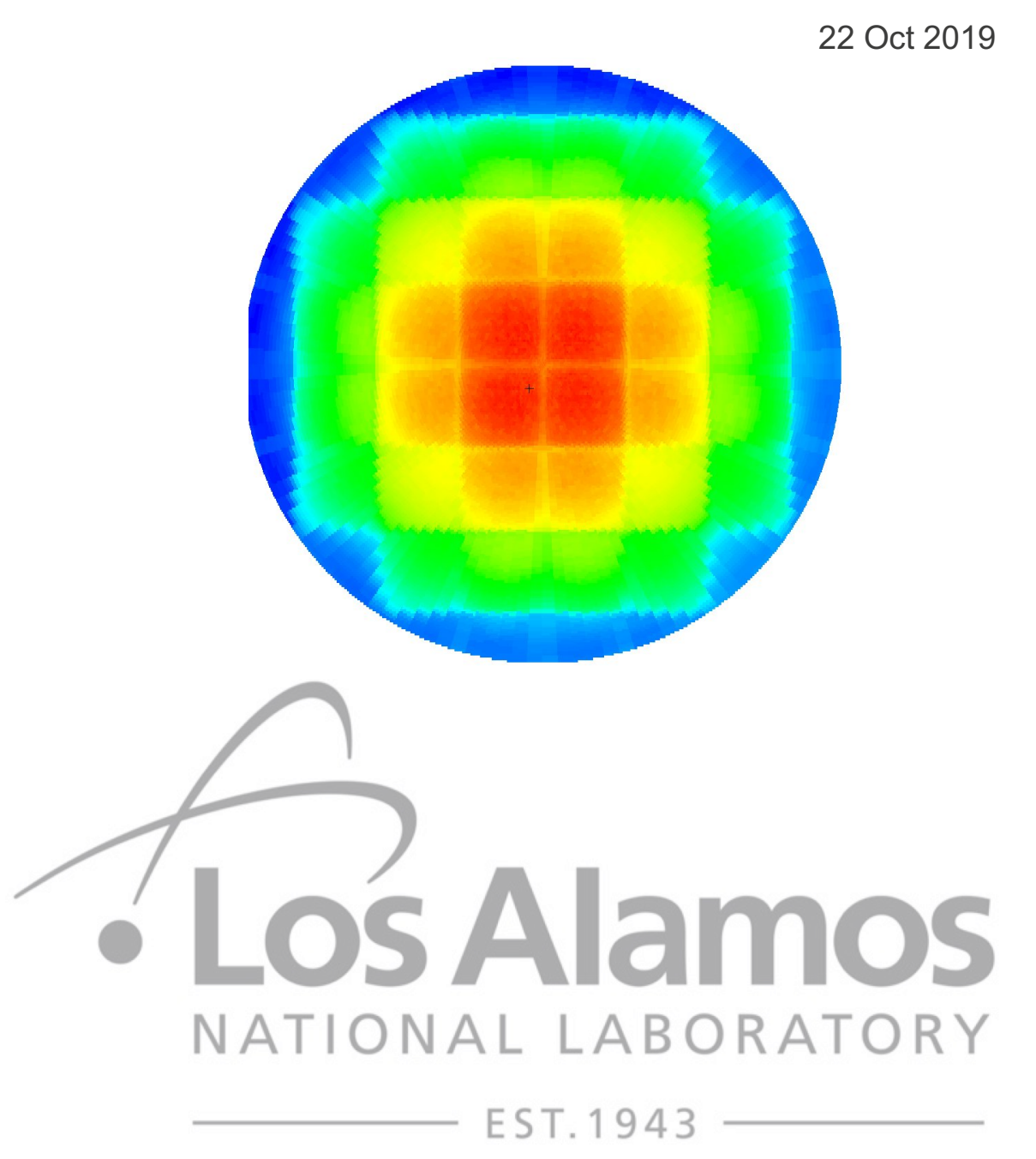

- Motivation

- Problem Description

- Feature Identification

- Discussion of Features

- Flat Flux Region Near Cask Centerline

- Periodic Depressions of Flux in Fuel Region

- Abrupt "Level-Off" Region

- Non-exponential Reduction in Overpack

- Asymmetric Flux

- Future Work 


\section{Enhanced analysis through complimentary reduced complexity analytic and computational modeling}

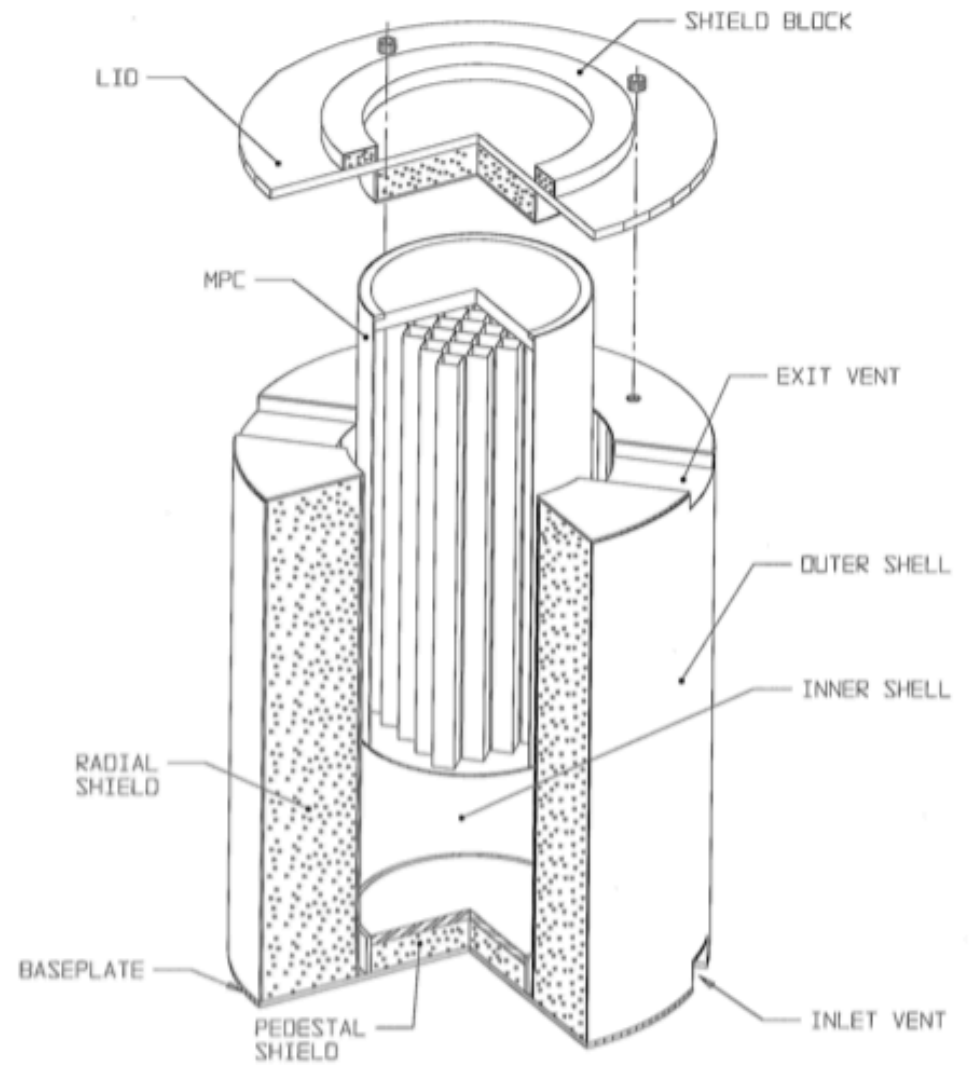

- Confidence in the accuracy of a simulation can be gained by

- Identifying features in results

- Explaining why those features exist

- Developed a detailed model of a Holtec HI-STORM 100 in MCNP

- Tallied the simulated neutron flux interior to the neutron cask as a function of radius

- Importance of interior flux:

- Flux exiting the cask is used to find significant quantities; dose, imaging, 'fingerprinting' casks

- Exterior flux carries convoluted information about internal effects

- Ultimate goal is to increase the confidence and enhance the analysis of the detailed model 


\section{A Holtec HI-STORM 100 spent fuel cask surrounded by air was simulated in MCNP as the detailed model.}

$\square$ Carbon Steel $\square$ Concrete $\square$ Dry Air $\square$ Stainless Steel $\square$ Helium

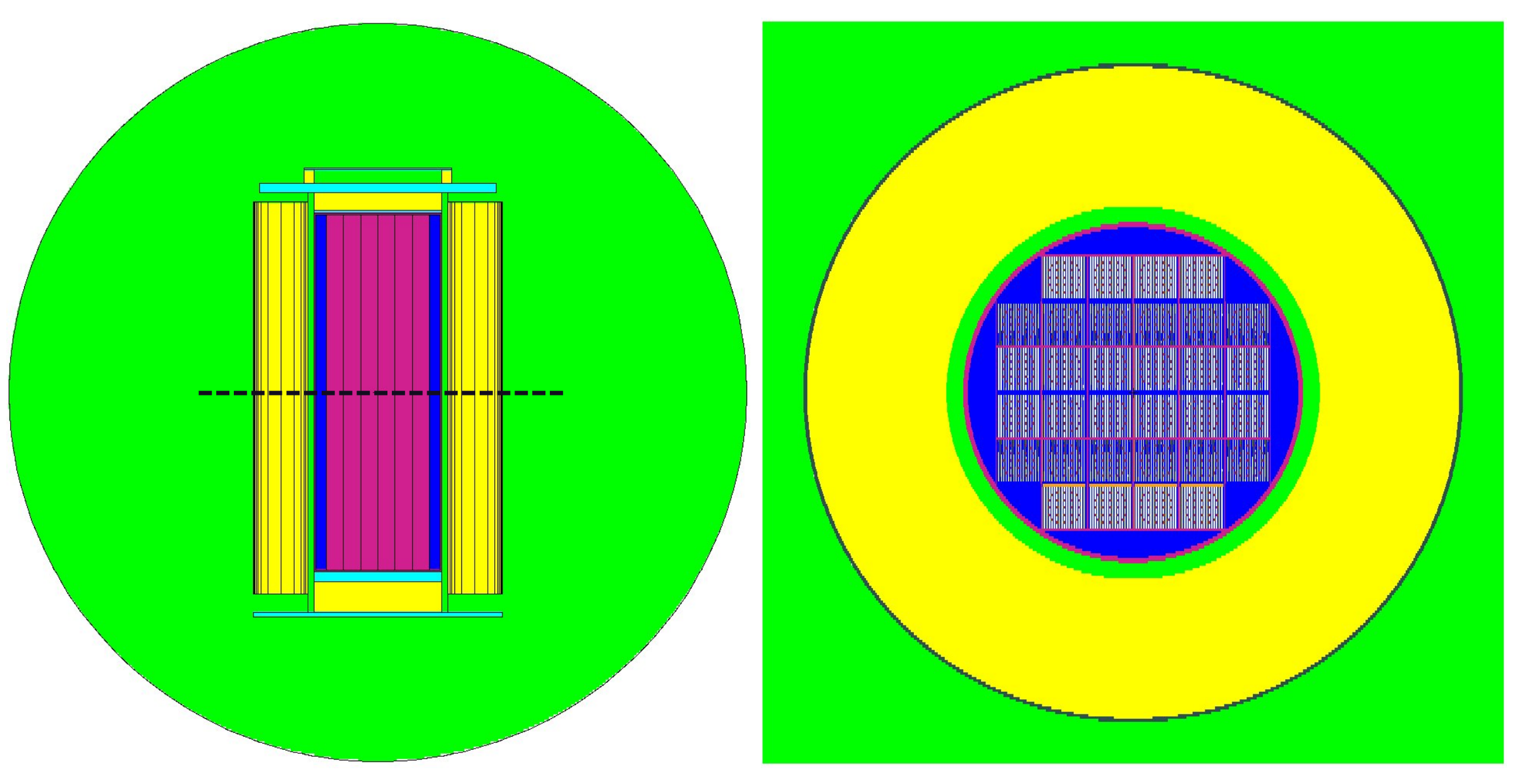


Each cell contains 264 fuel rods and 25 instruments as well as two neutron absorbing pads.

$\square$ Fuel Rod $\square$ Instrument $\square$ Cladding $\square$ Stainless Steel $\square$ Helium $\square$ Neutron Absorber

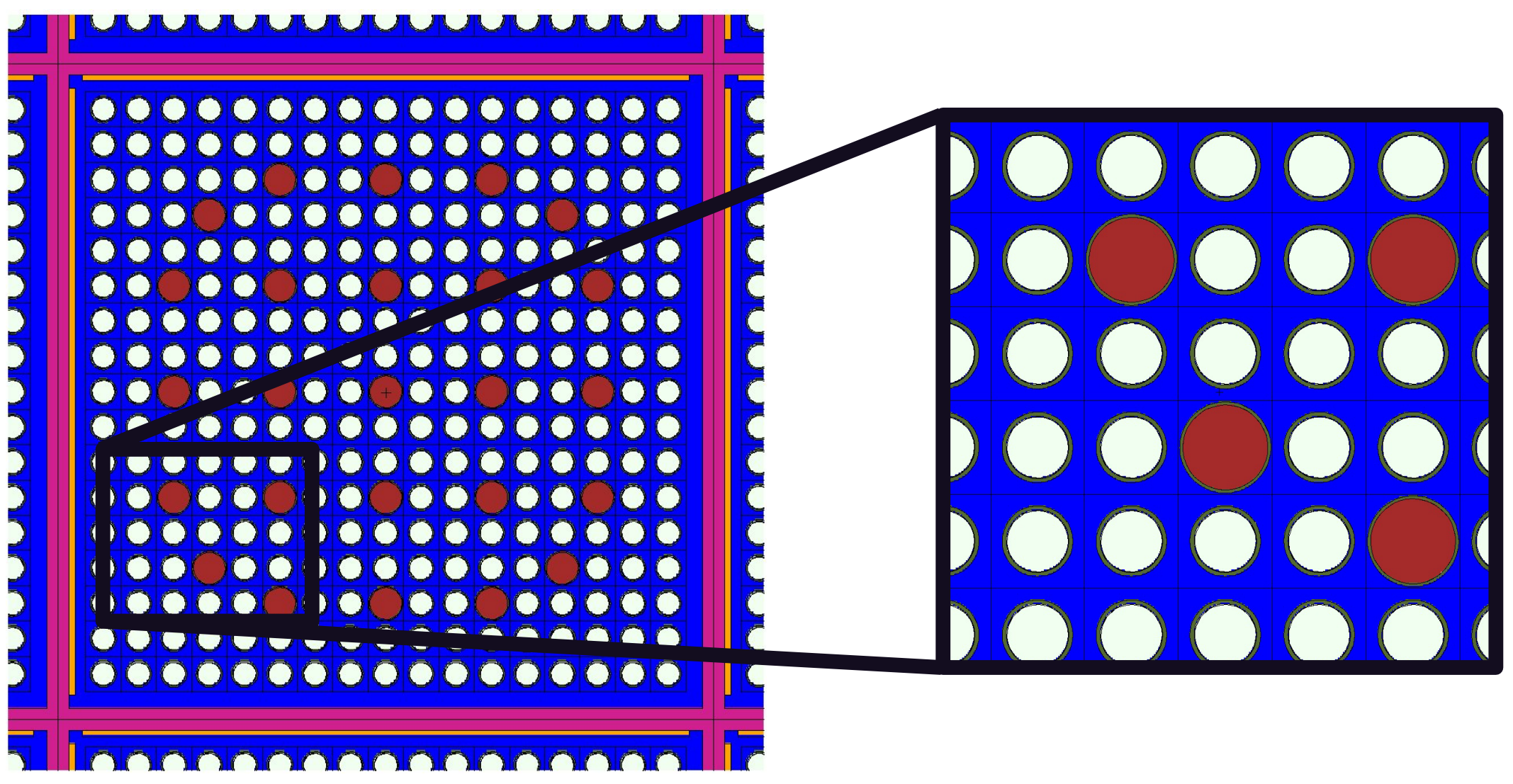




\section{Neutron attenuation predominantly occurs in concrete annulus of the overpack}

Spatial Variation of Flux

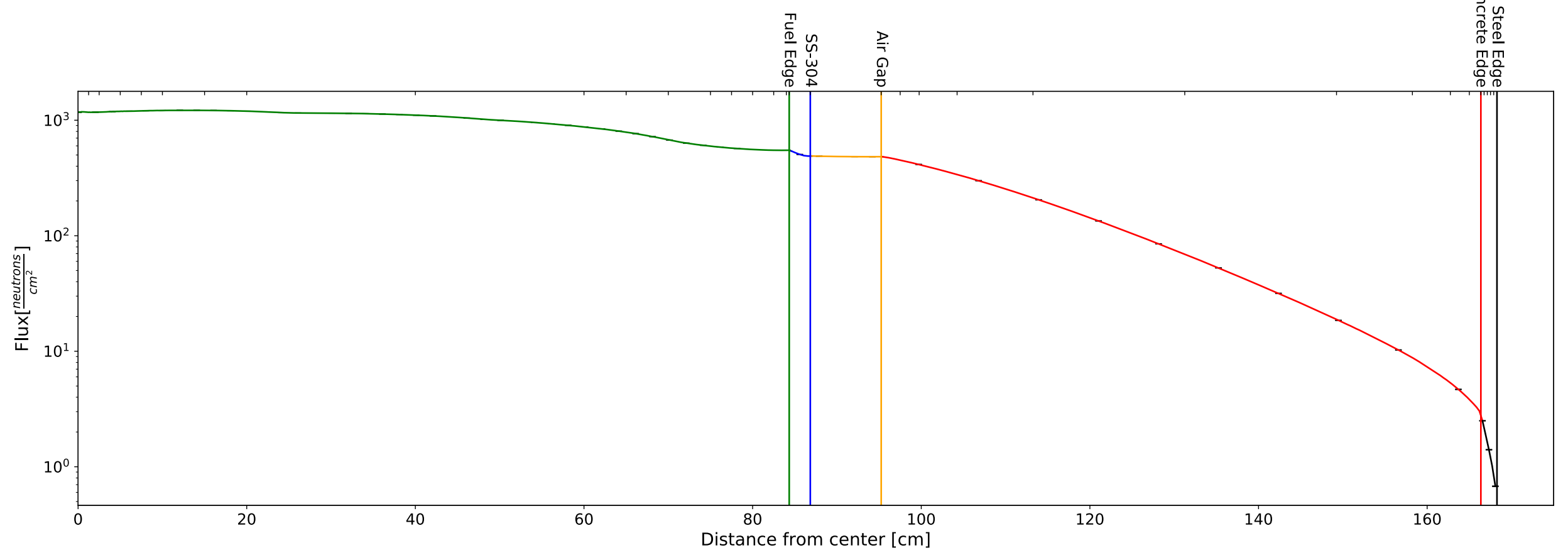

- MCNP simulated flux through the spent fuel cask

- Cylindrical FMESH $1 \mathrm{~mm}$ radial mesh spacing

- Air gap shows little reduction on neutron flux - possibly neglect in modelling

- Flux decreases two orders of magnitude in concrete 


\section{$\sim 1.5 \%$ reduction in flux across first $25 \mathrm{~cm}$}

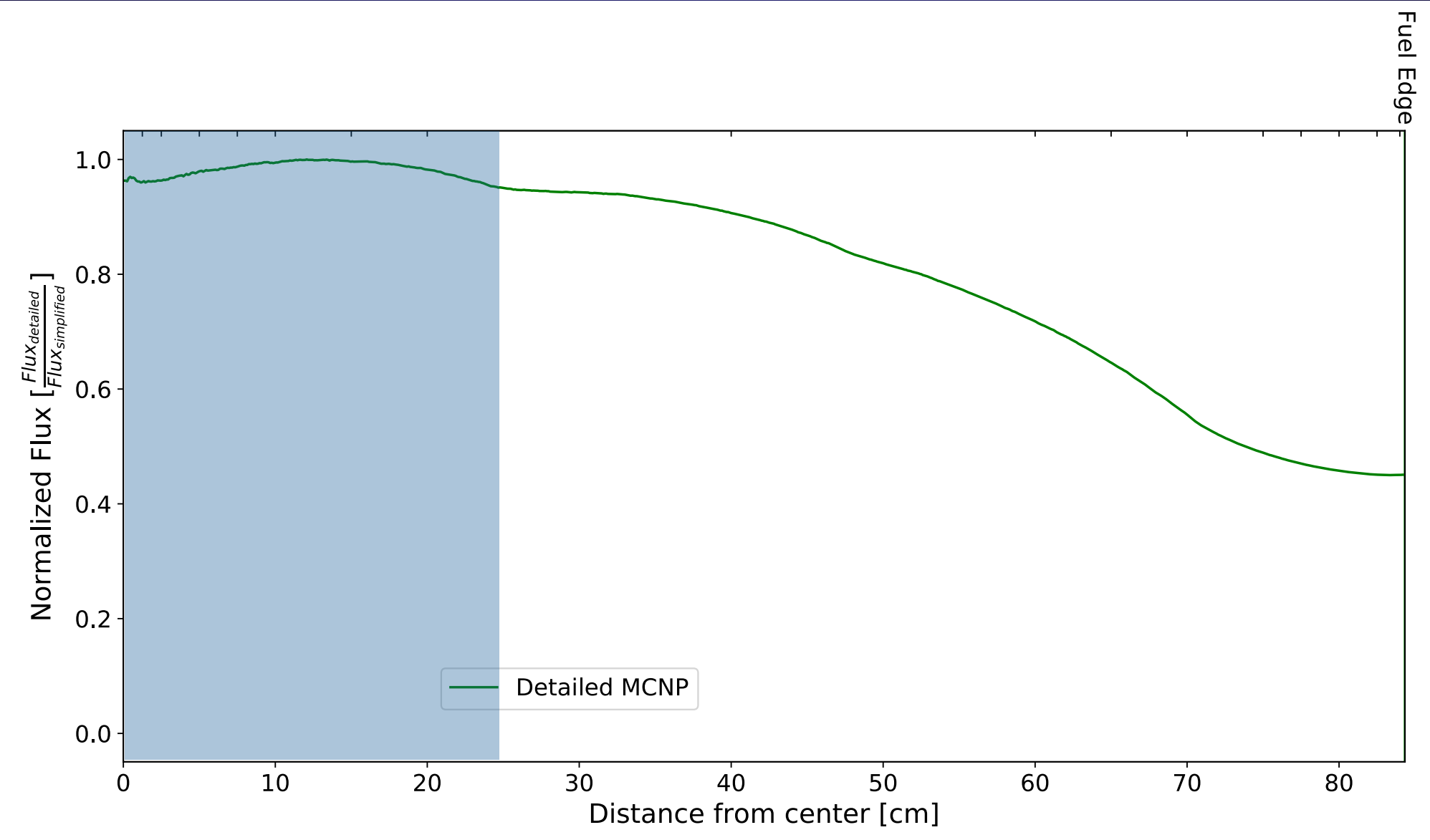

1. "Flat" Flux Region 


\section{$\sim 2 \%$ decrease at three locations}

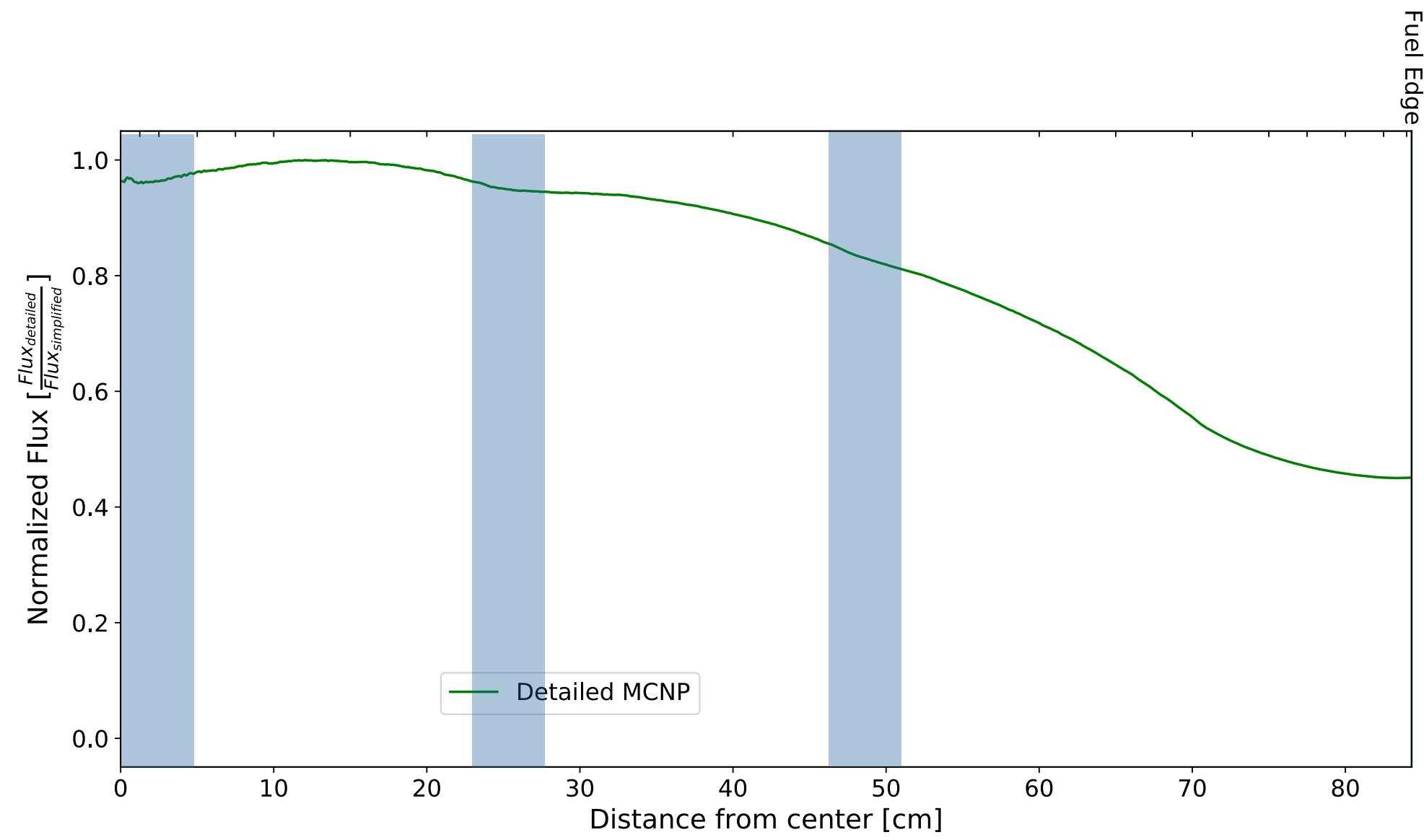

1. "Flat" Flux Region

2. Periodic Depressions 


\section{$\sim 3 \%$ decrease in flux over last $10 \mathrm{~cm}$ in fuel region}

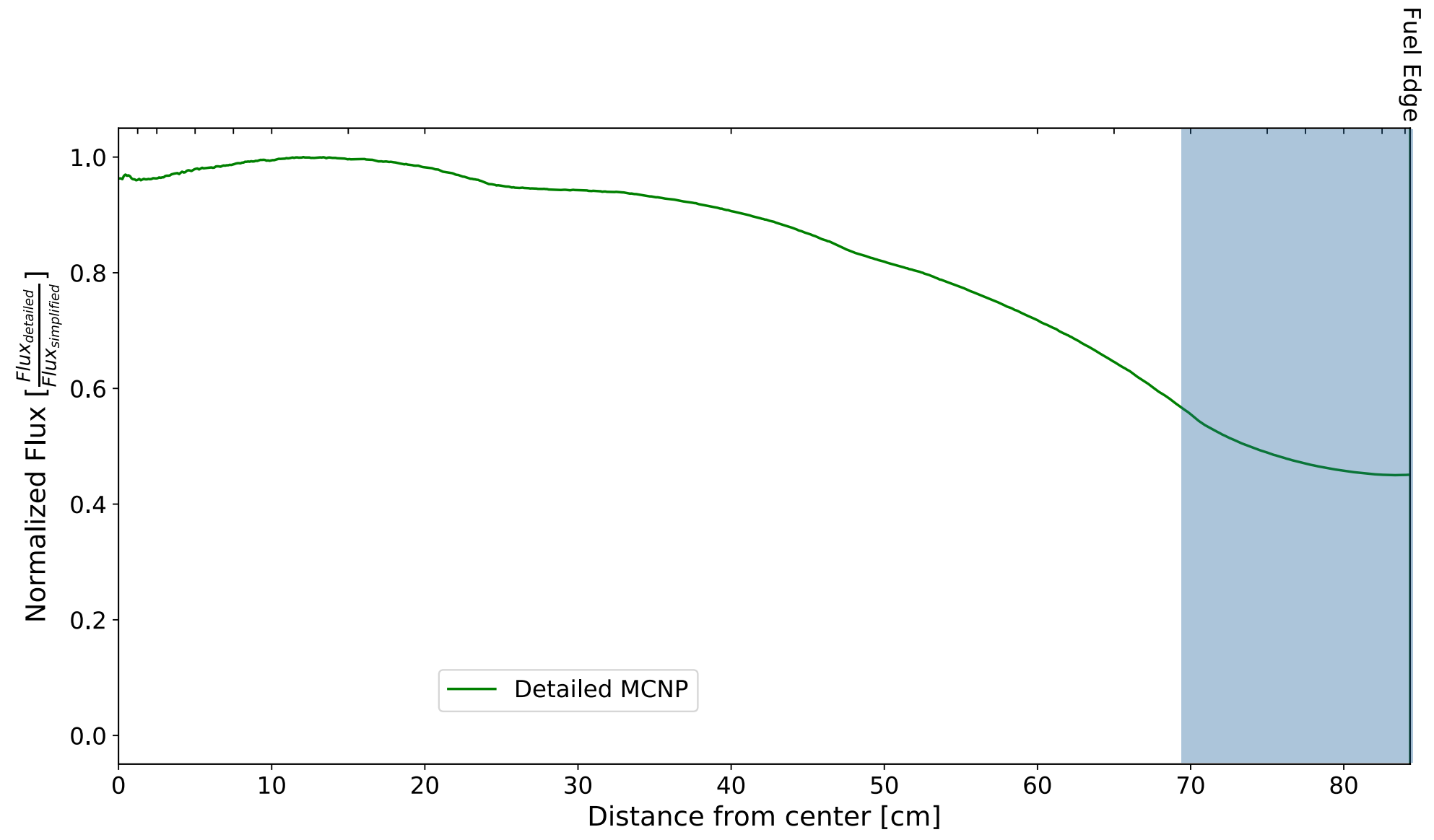

1. "Flat" Flux Region

2. Periodic Depressions

3. Abrupt "Level-Off" Region 


\section{Exponential decay in steel, however flux in concrete decays non-exponentially over two orders of magnitude}

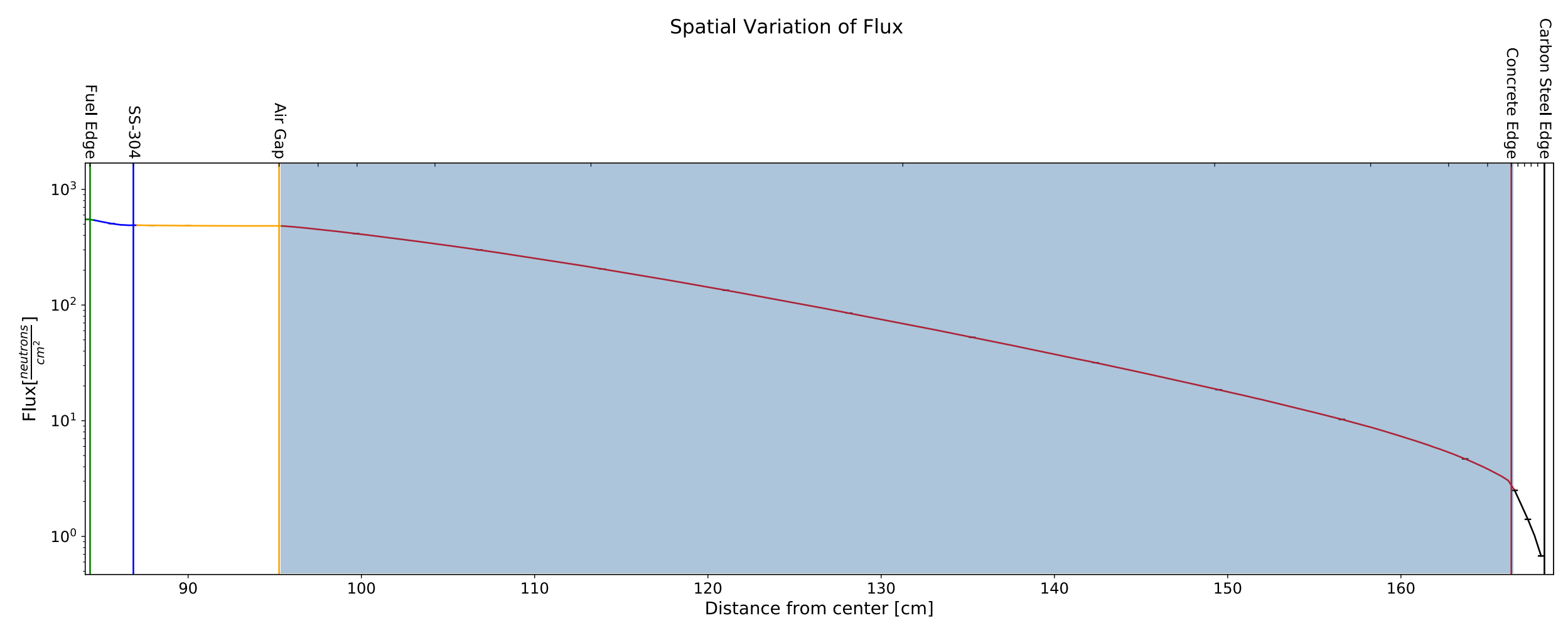

1. "Flat" Flux Region

2. Periodic Depressions

3. Abrupt "Level-Off" Region
4. Non-Exponential Reduction in Overpack 
Flux in bottom-right region is $\sim 10 \%$ higher than-top left region at the exiting surface of the fuel region

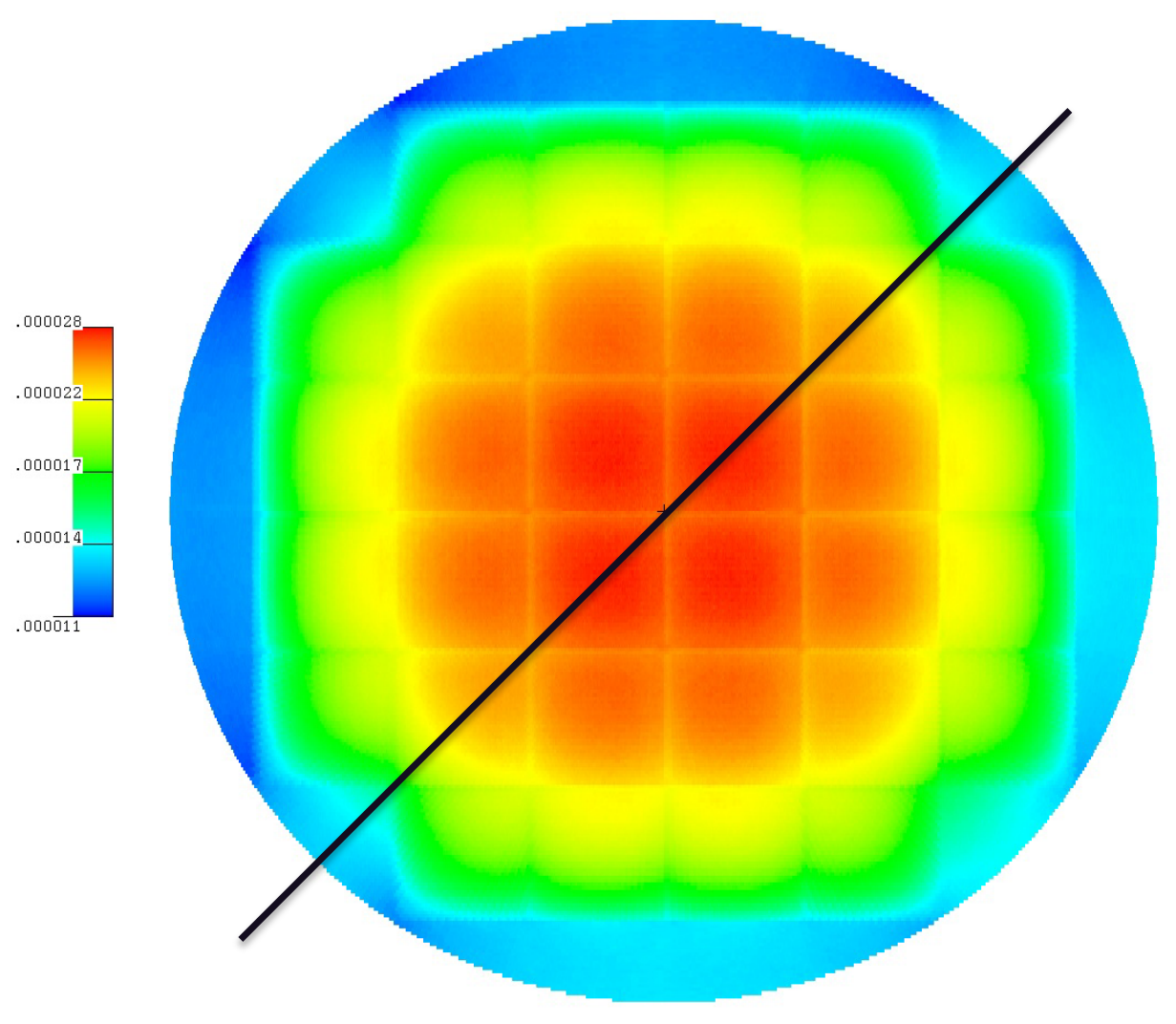

1. "Flat" Flux Region

2. Periodic Depressions

3. Abrupt "Level-Off" Region
4. Non-Exponential Reduction in Overpack

5. Asymmetric Flux 


\section{Summary of Presentation}

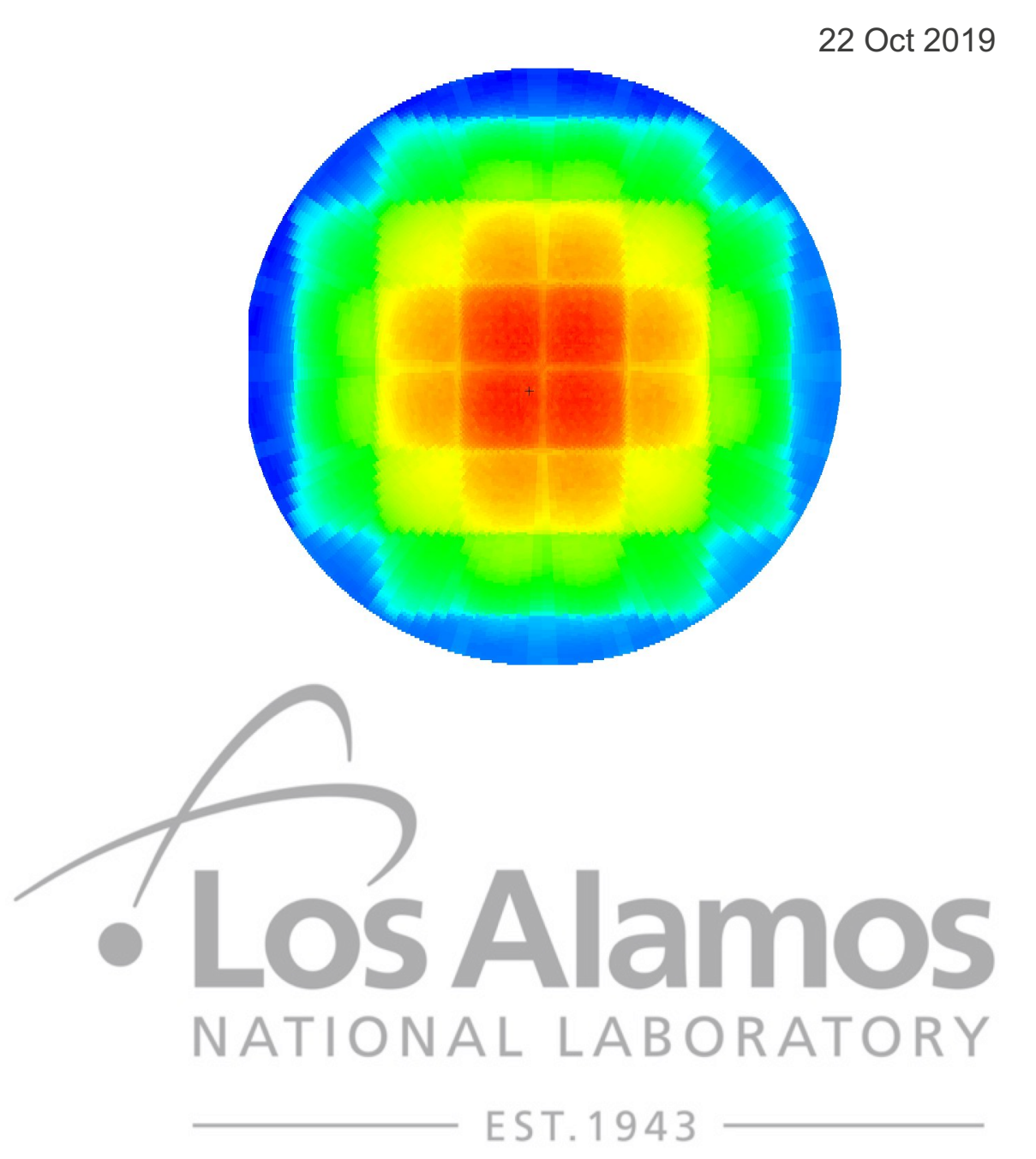

- Motivation

- Problem Description

- Feature Identification

- Discussion of Features

- Flat Flux Region Near Cask Centerline

- Periodic Depressions of Flux in Fuel Region

- Abrupt "Level-Off" Region

- Non-exponential Reduction in Overpack

- Asymmetric Flux

- Future Work 


\section{Flux profile is fairly constant, within $2 \%$ over first $25 \mathrm{~cm}$ away from the centerline}

- There is less than a $2 \%$ decrease in the flux over the first $25 \mathrm{~cm}$

- The flatness of the flux alludes to:

- Small losses due to absorption

- Neutrons are diffusing

- Diffuse source term may mean isotropic flux

- Geometric effects may be less important than material properties

- Diffusion Equation!

- Single energy group (> $100 \mathrm{keV}$ )

-1-D radial - little axial variation at center of cask

- In conjunction with analytic model

- MCNP model with homogenous fuel region

$$
\frac{\propto}{D B^{2}}\left(1-\frac{I_{0}(B r)}{I_{0}(B \tilde{r})}\right)
$$

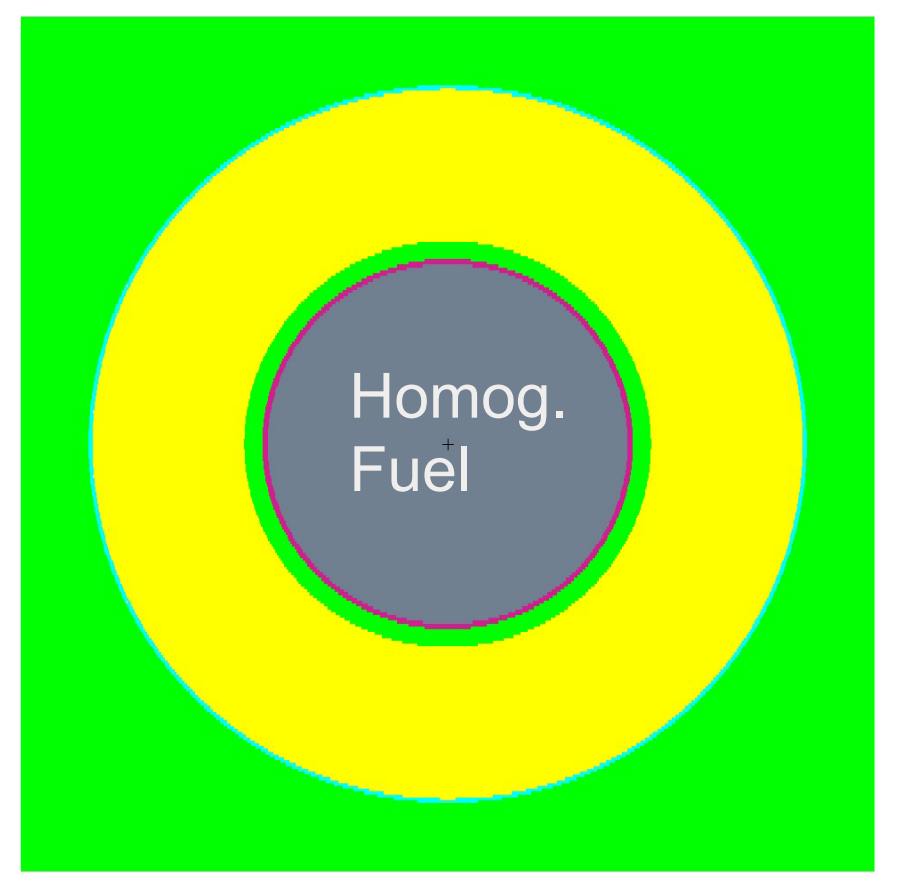




\section{Diffusion physics is driving neutron transport near cask centerline}

- Over first $50 \mathrm{~cm}$,

- Homogenous model overpredicts flux by $\sim 1.20-1.25 x$

- Analytic model overpredicts flux by $\sim 1.1-1.2 x$

- The models poorly predict the flux at the boundary

- Material properties are dominant physics (material buckling)

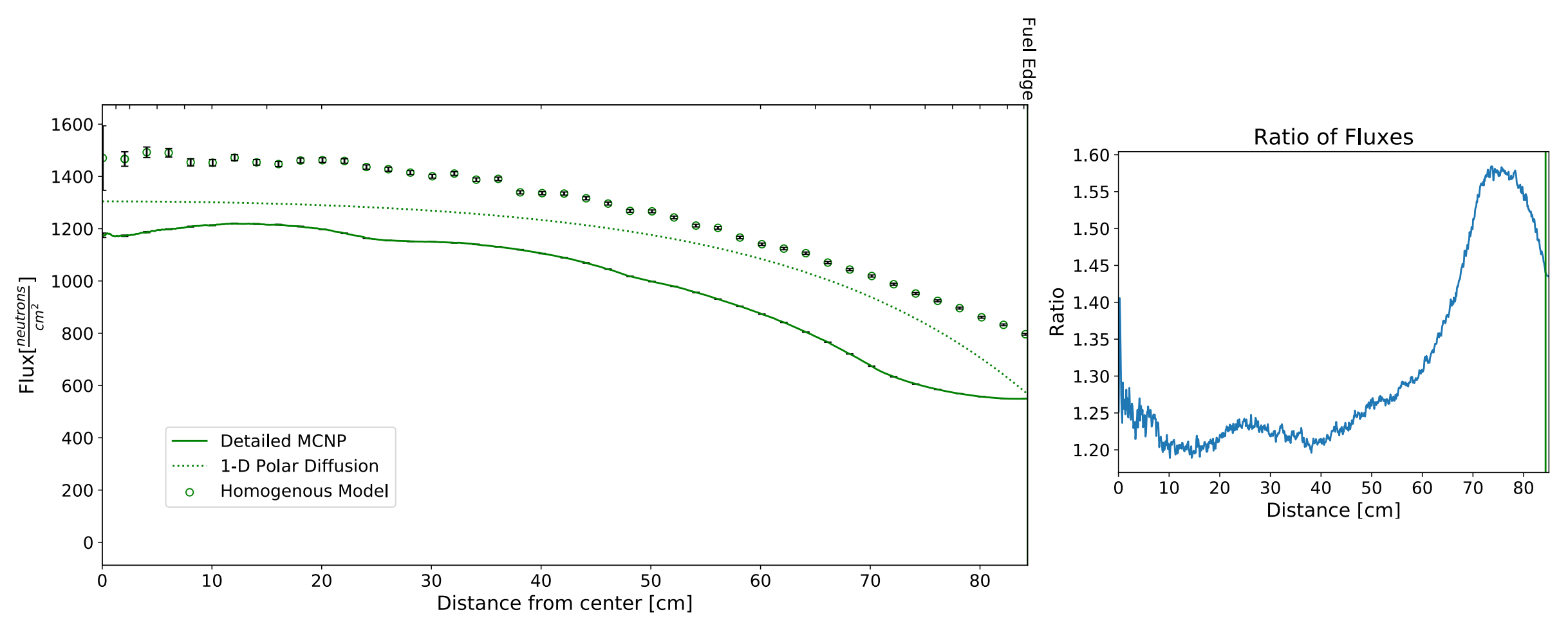




\section{Materials between cells probably cause}

\section{local reductions in flux}

- There are three minor depressions in the flux

- These depressions were thought to be caused by steel and neutron absorbing materials between fuel cells

- Locations of depressions are near basket cross bar locations

- A 1-D cartesian model was developed in MCNP

- Layered stainless steel (SS), a neutron absorbing material, and homogenized fuel

- Future work will add a multigroup discrete ordinates equation analytic model

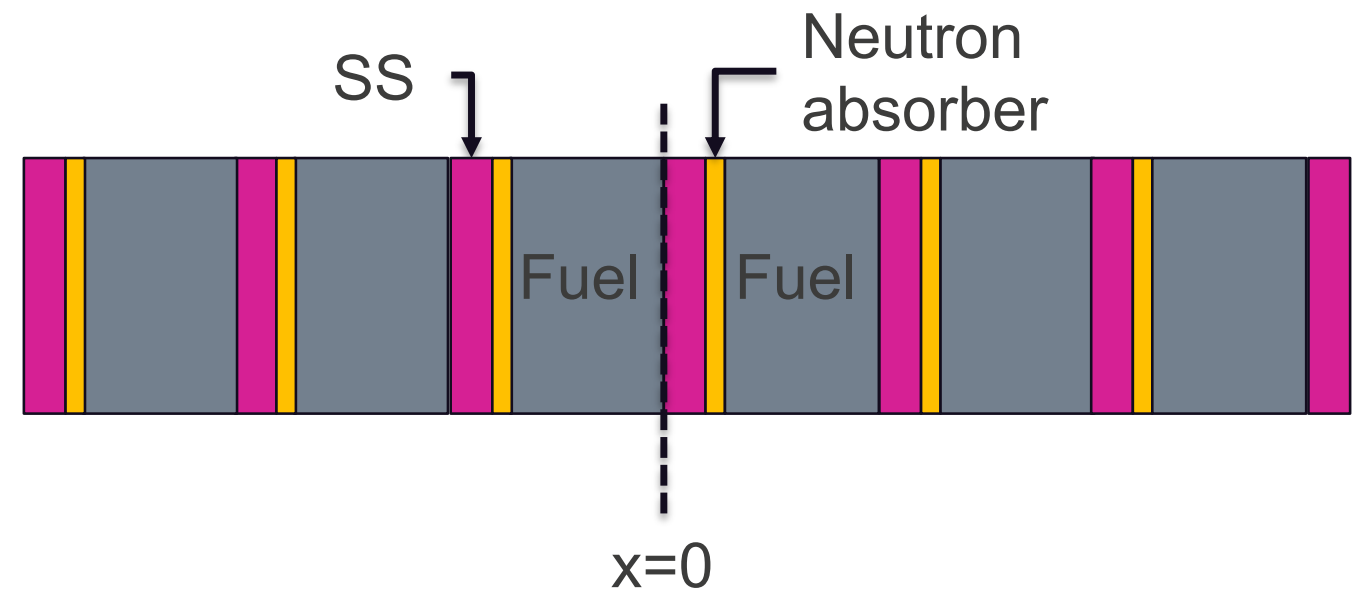




\section{Basket structures cause 1-2\% local reduction in neutron flux}

- The space between fuel containing regions sees a reduction in flux between $1 \%$ and $2 \%$

- Add 1-D transport
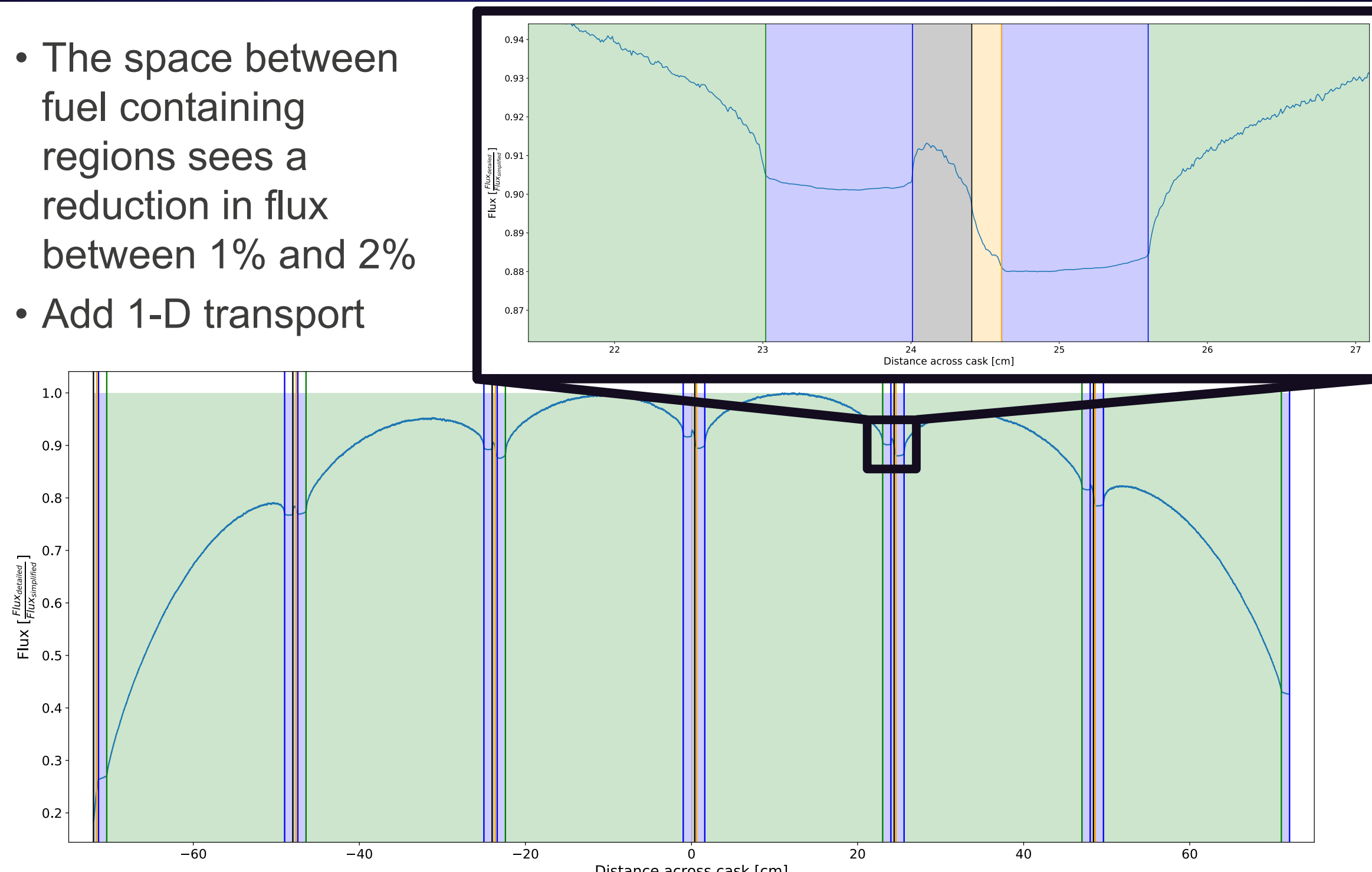


\section{The flux becomes nearly flat within the last $15 \mathrm{~cm}$ of the fuel region}

- Previous homogeneous model did not capture "leveling-off" region at $\sim 70 \mathrm{~cm}$

- Previous model did not have a streaming region

- Detailed model has helium surrounding the lattice of fuel cells

- By adding a helium gap, neutrons should be able to stream

- Helium gap causes the flux to level-off

- Helium model

- Homogenous fuel region preserves volume of original fuel cells

- Fuel definition accounted for reduced helium in homogenous fuel

- Analytic model updates

- New radius was used in diffusion model

- Neutrons were allowed to stream through helium gap

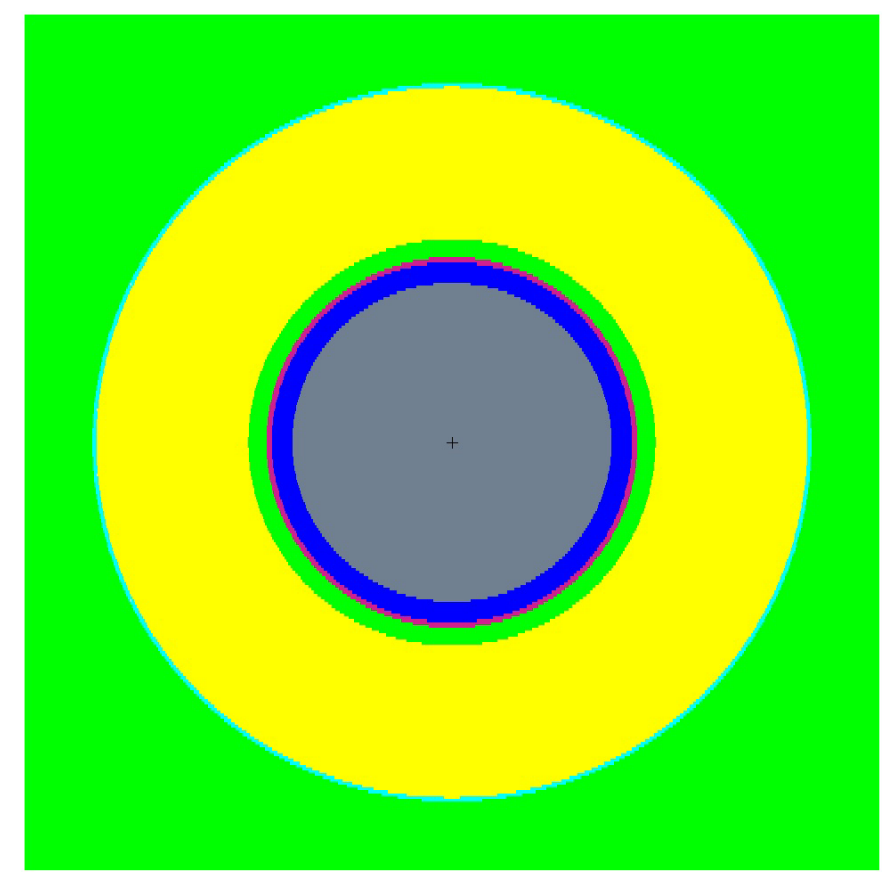




\section{Helium surrounding the fuel cells allows for neutrons to free stream - flattening flux}

- Helium model overpredicts the flux by $<10 \%$ over first $50 \mathrm{~cm}$

- Diffusion equation solution appears to capture "level-off" region

- Both models show an improvement in capturing the physics in the fuel region

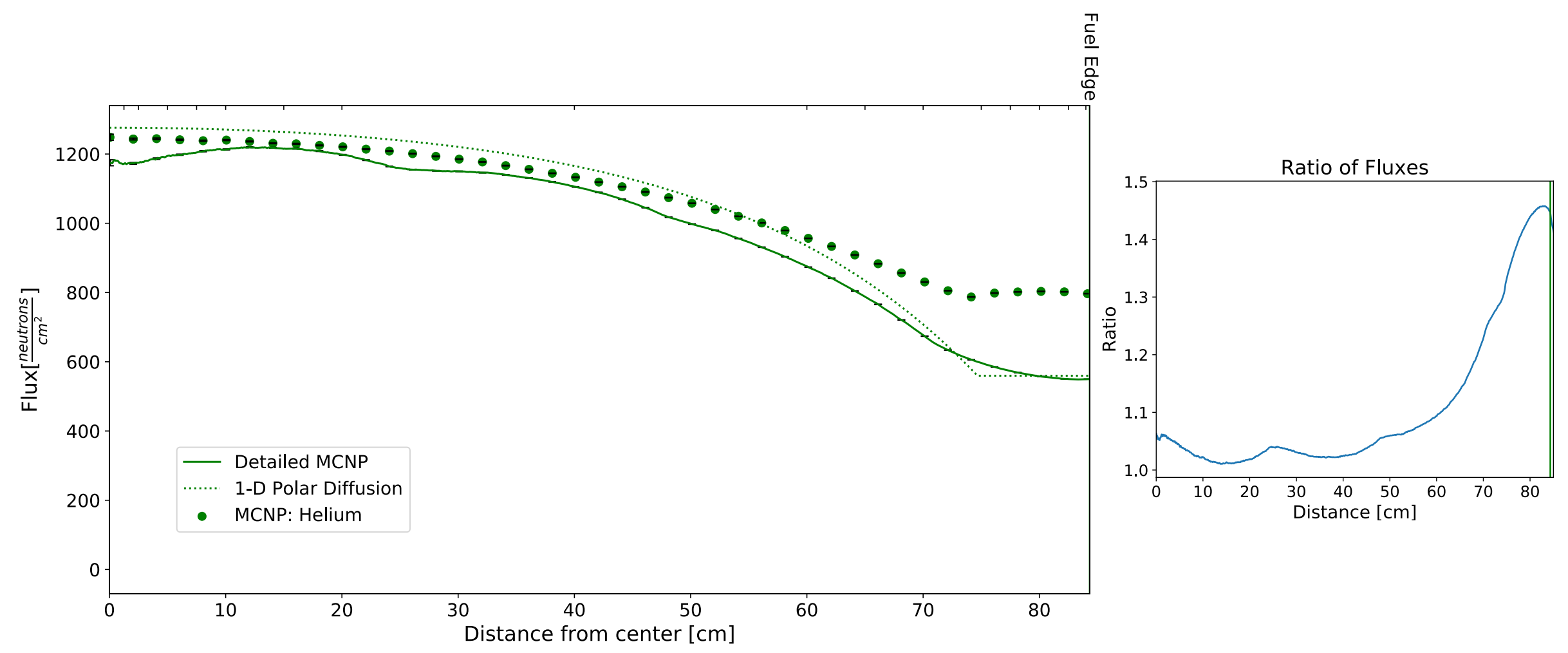




\section{Previous efforts led to a new model designed to best reproduce flux in detailed model}

- A new model was made from identifying the cause of the previous features

- Cruciform with helium gap model

- Cell based geometry was preserved

- Fuel rods were homogenized inside each fuel cell

- Each cell contains a helium gap to allow for streaming from individual fuel blocks

- The volume of the original fuel lattice was preserved during homogenization

- Simulations took 481.79 minutes for 1E7 particles

- Detailed model took 756.05 minutes for same number of particles

$-\sim 1.57 x$ speed up

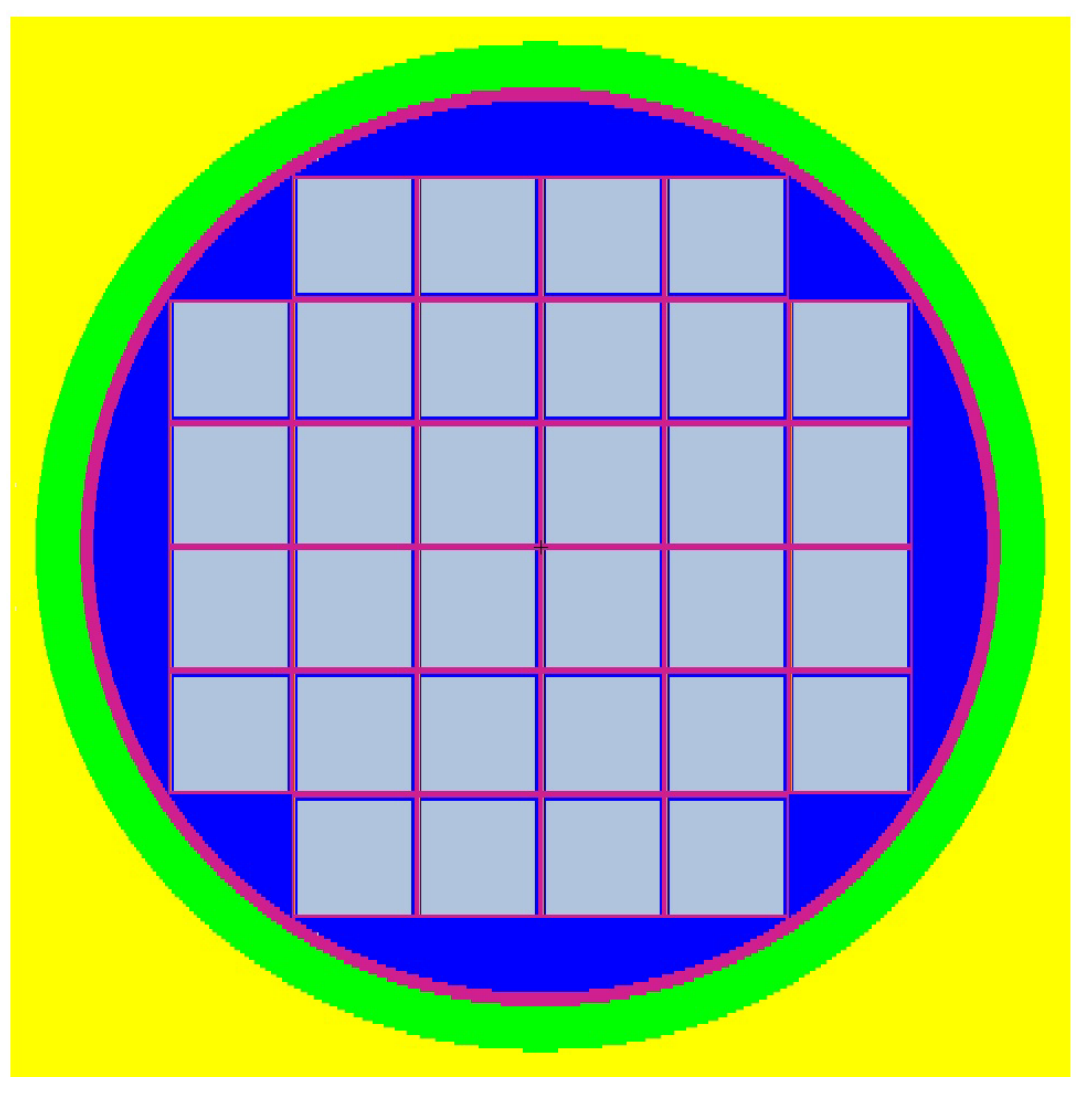




\section{$<10 \%$ difference between flux in cruciform with helium model and detailed model}

- The cruciform with helium gap model agrees with the detailed model within $\sim 5-7 \%$ for the entirety of the fuel region

- Flux depressions due to basket structure are captured

- Free streaming region is captured within $5 \%$ difference

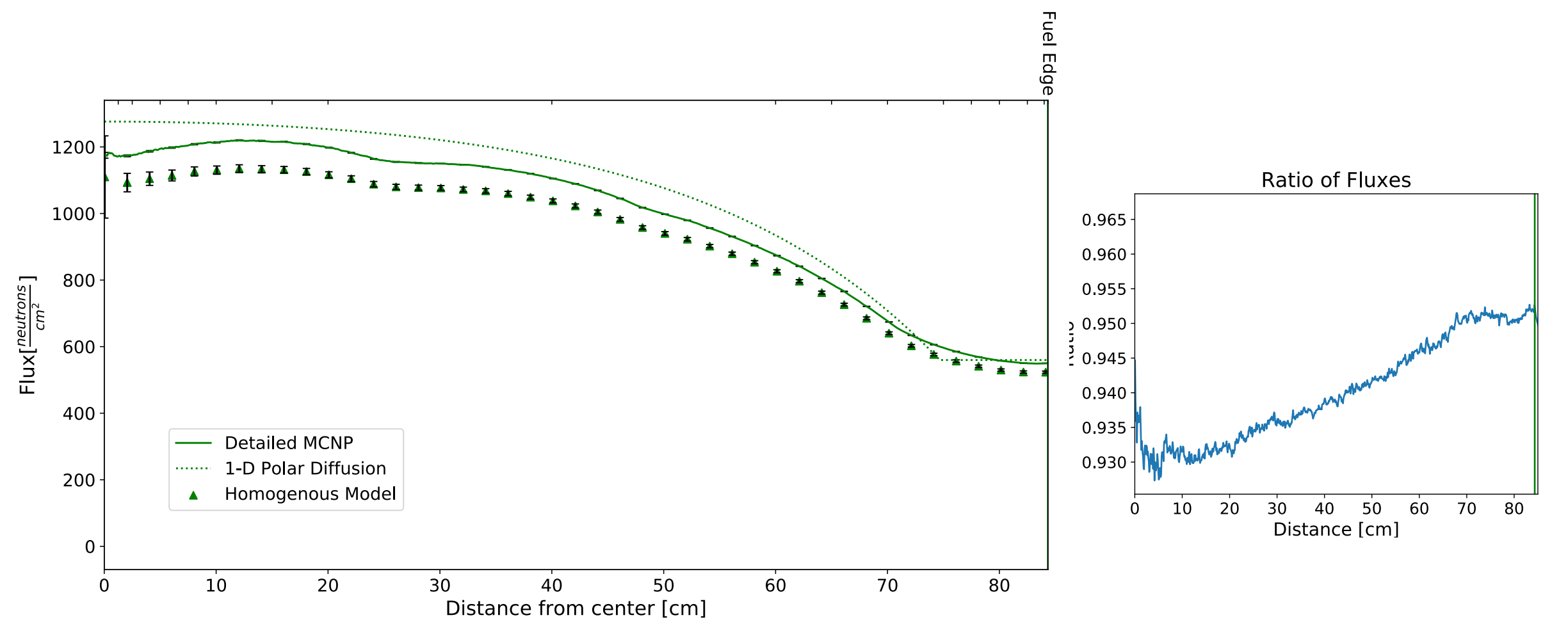




\section{The non-exponentially decaying nature of the neutron flux suggests analytic modeling}

- Purely analytic modeling

- Based on multigroup discrete ordinance equations

- Originally, two energy groups and two directions were chosen

- Analytic modeling allows for physics to be "turned off/on"

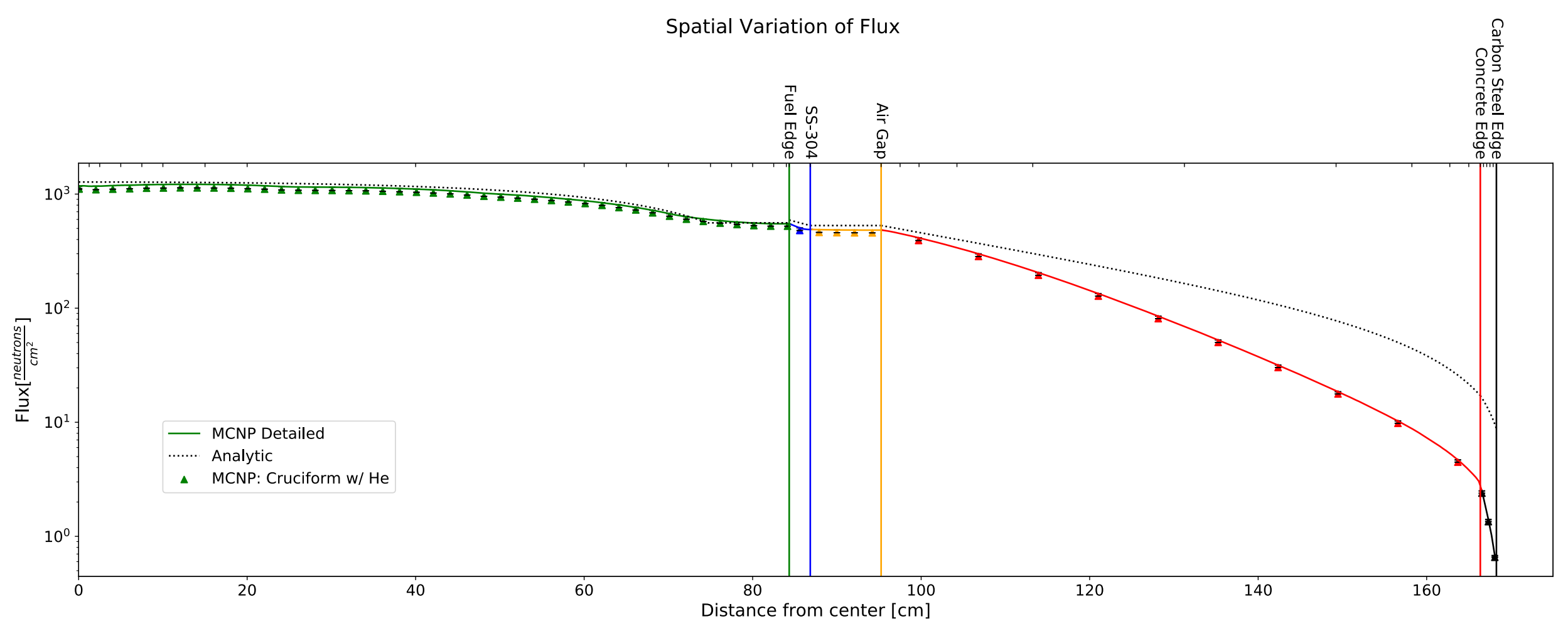




\section{More than two directions are needed to accurately model the flux in the concrete}

- Two directions does not adequately capture physics in concrete

- To see if more angles will better approximate detailed model

- Residual calculation

Begin by defining the 1-D multigroup discrete ordinates Boltzmann operator with isotropic scattering as:

$\mathcal{B}_{N}^{G}\left\{\phi_{N}^{G}\right\}=\mu_{n} \frac{d}{d x} \phi_{n}^{g}+\Sigma_{t, n}^{g} \phi_{n}^{g}-\sum_{g^{\prime}}^{G} \frac{\Sigma_{s}^{g^{\prime} \rightarrow g}}{2} \sum_{n^{\prime}}^{N} w_{n^{\prime}} \varphi_{n^{\prime}}^{g^{\prime}}-S_{n}^{g}=$ Residual,

where $\mathcal{B}_{2}^{2}\left\{\phi_{2}^{2}\right\}=0$. Using the solution to a multigroup discrete ordinance equation with two energy groups and two directions $\left(\phi_{2}^{2}\right)$, we can create a pseudo-flux solution with four directions and two energy groups $\left(\tilde{\phi}_{4}^{2}\right)$. Since the pseudo-flux is not the true solution to $\mathcal{B}_{4}^{2}\left\{\phi_{4}^{2}\right\}$, there will be a non-zero residual.

$$
\mathcal{B}_{4}^{2}\left\{\tilde{\phi}_{4}^{2}\right\} \neq 0
$$




\section{More than two directions are needed to accurately model the flux in the concrete}

- Residual of the fast flux tells us we need more angles

- Residual of the thermal flux is two orders of magnitude lower than that of the fast flux
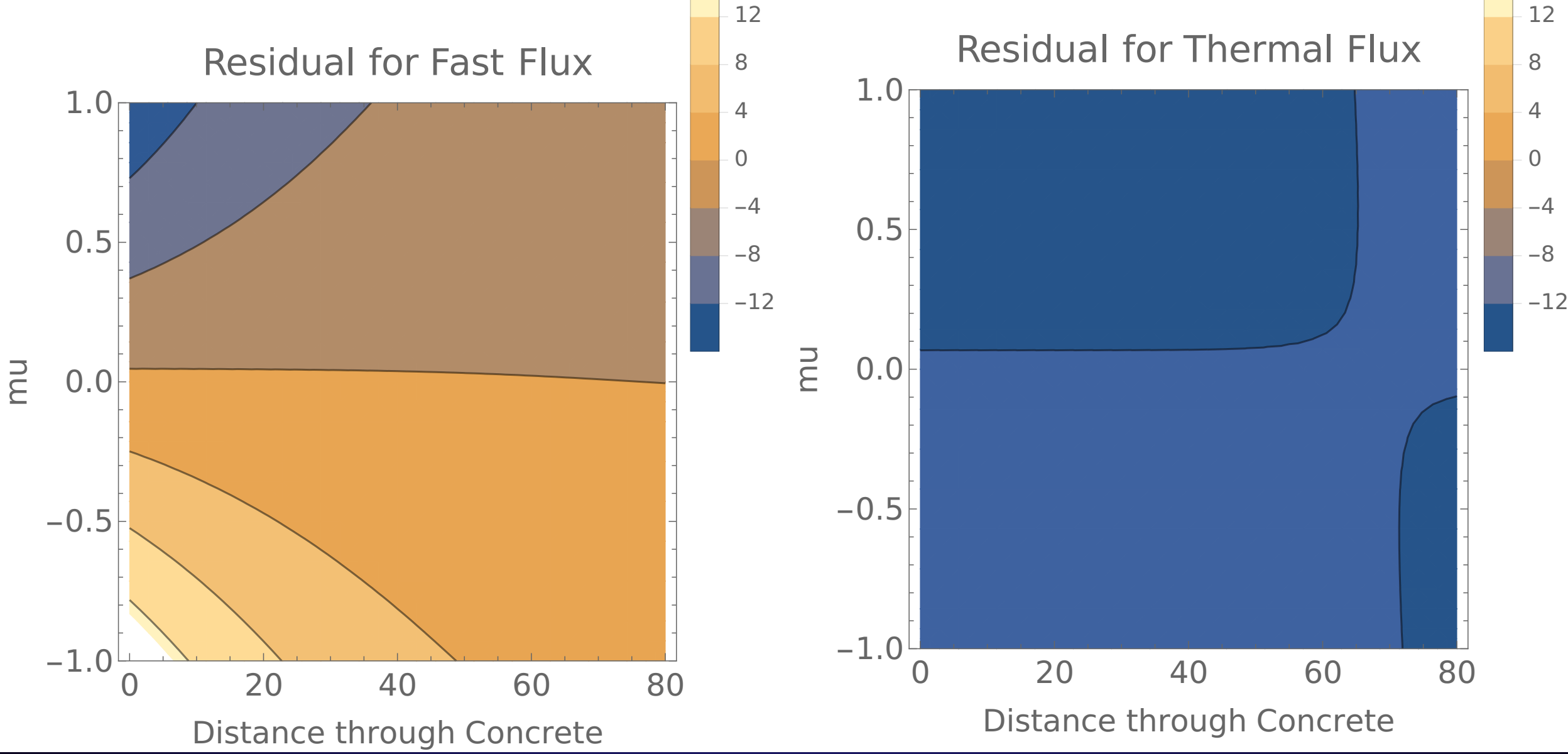


\section{The flux is not symmetric around the outside of the fuel region}

- The flux of the lower right half of cask is higher than the upper left half

- The asymmetric loading of neutron absorbing pads within fuel cells is suspected to cause the uneven flux
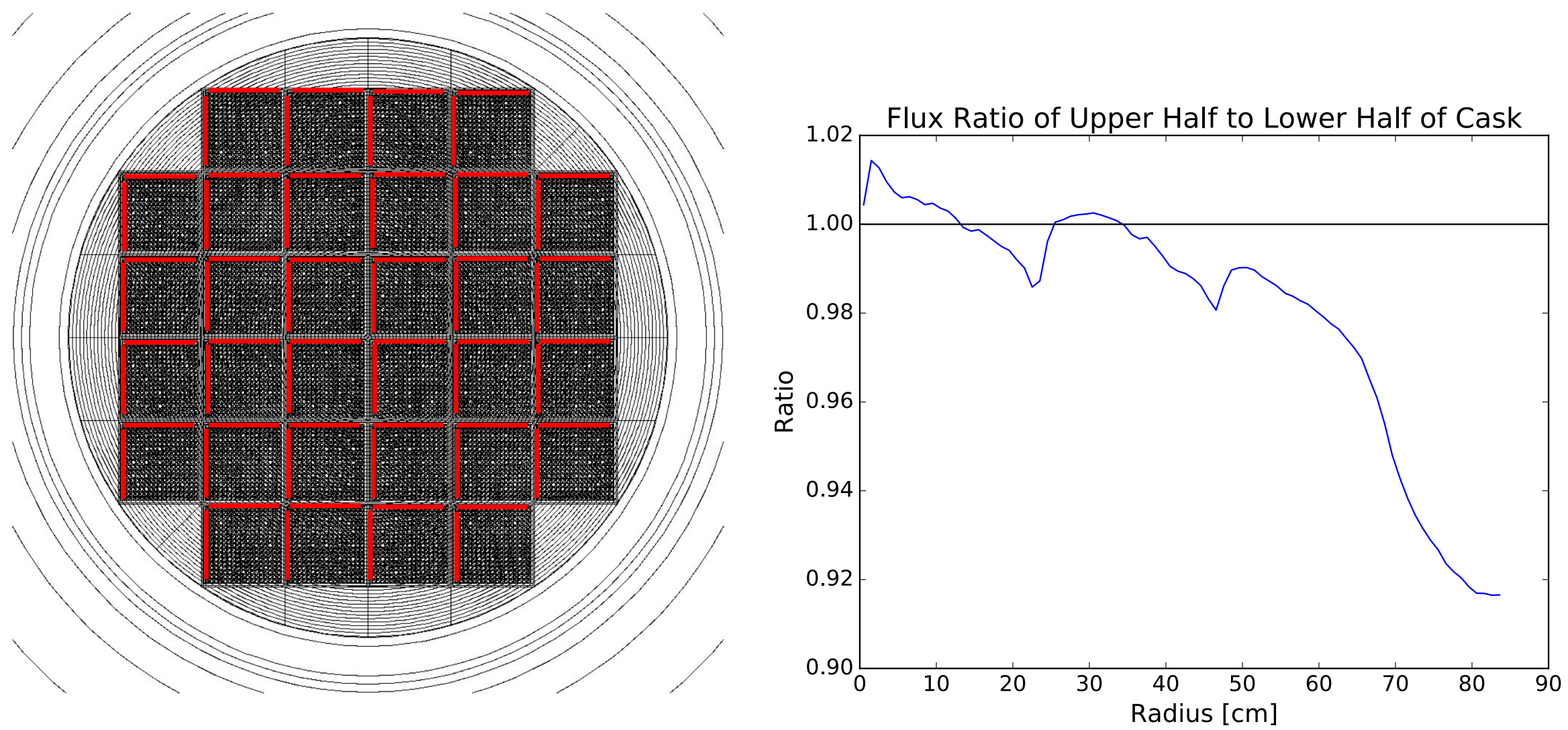


\section{Asymmetry of internal structure (single neutron absorbing pad) causes asymmetry}

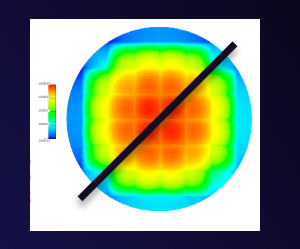

-1-D array model shows

- The flux leaving the left surface is lower than the right

- The effect is due to an extra layer of the neutron absorber
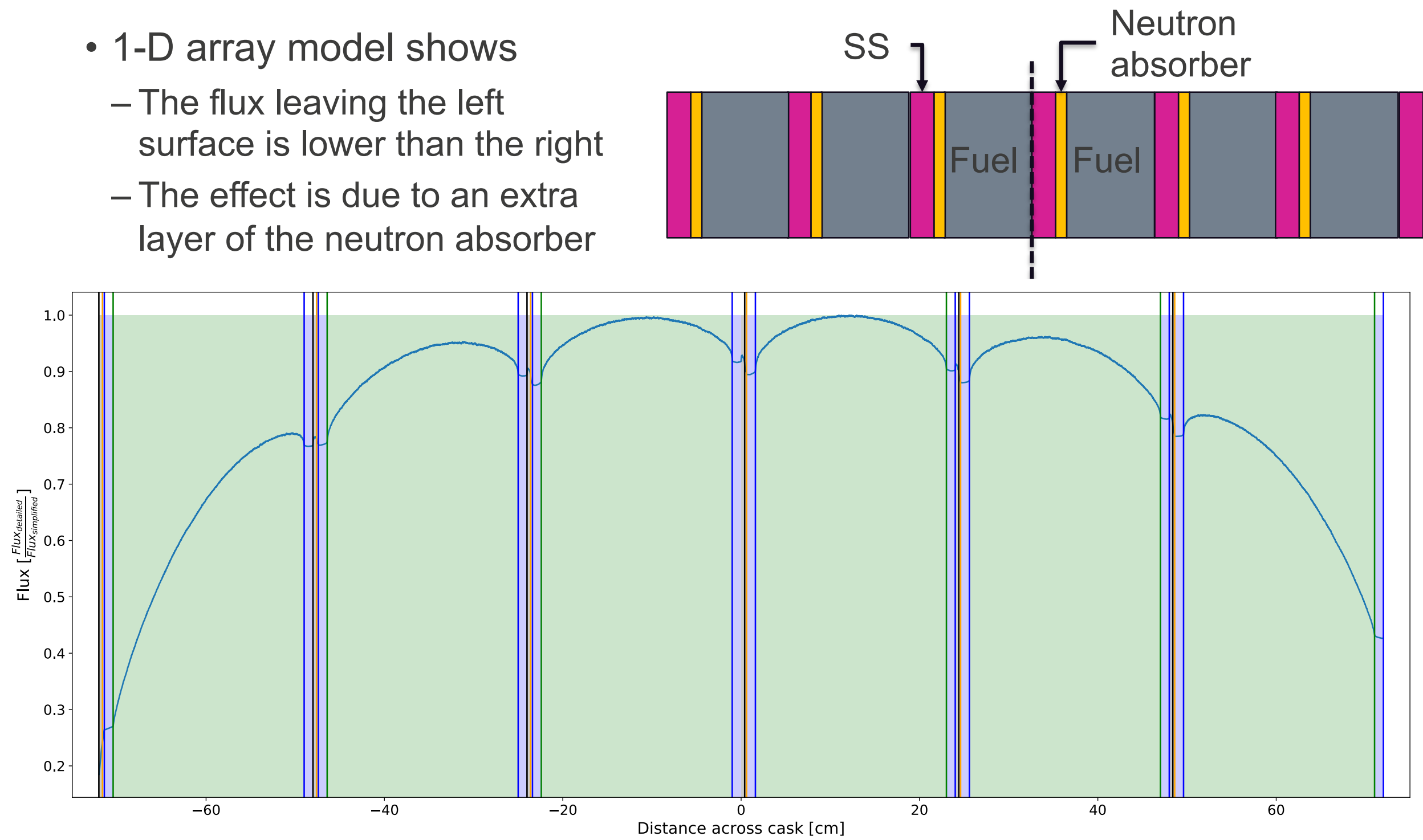


\section{Replacing steel and neutron absorbing structure leads to a symmetric flux leaving fuel region}

- Further investigation replaced the neutron absorber and stainless steel and fuel rods with void

Void for steel and neutron absorber

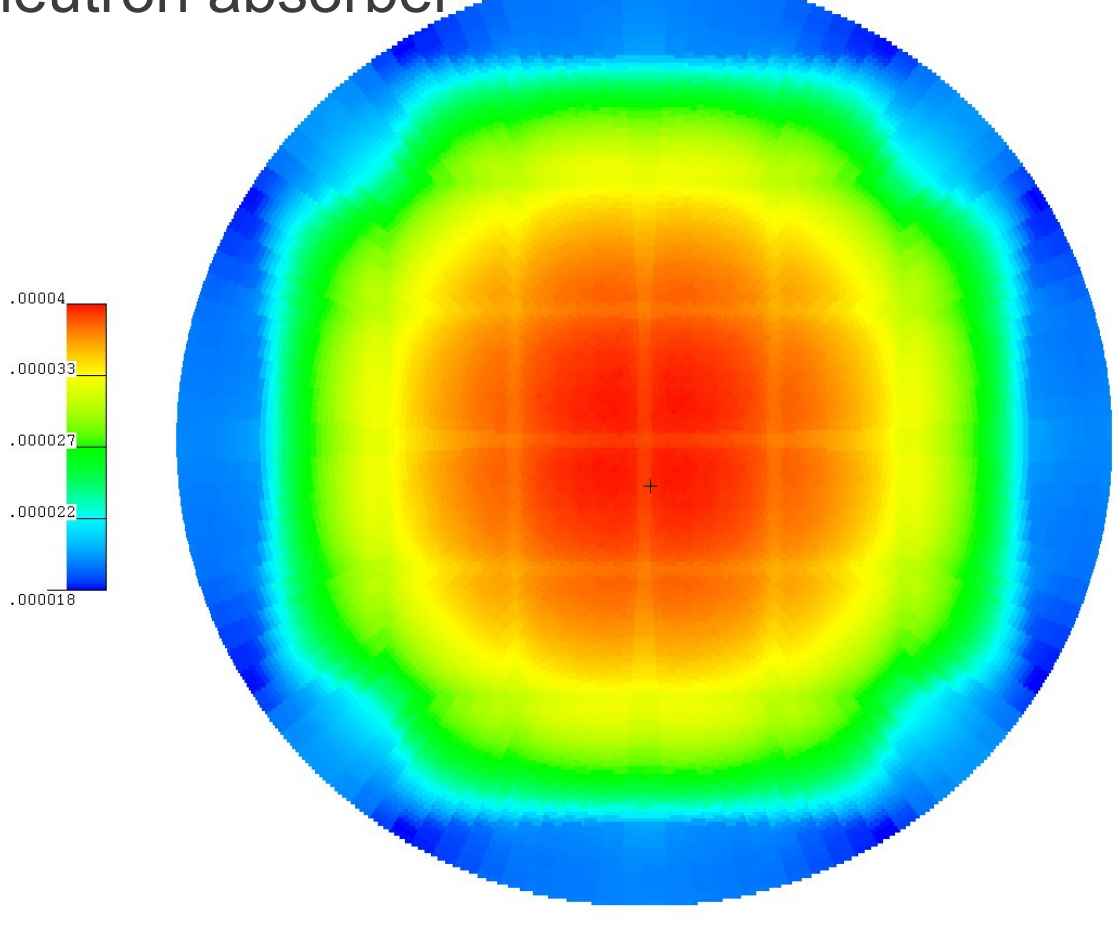

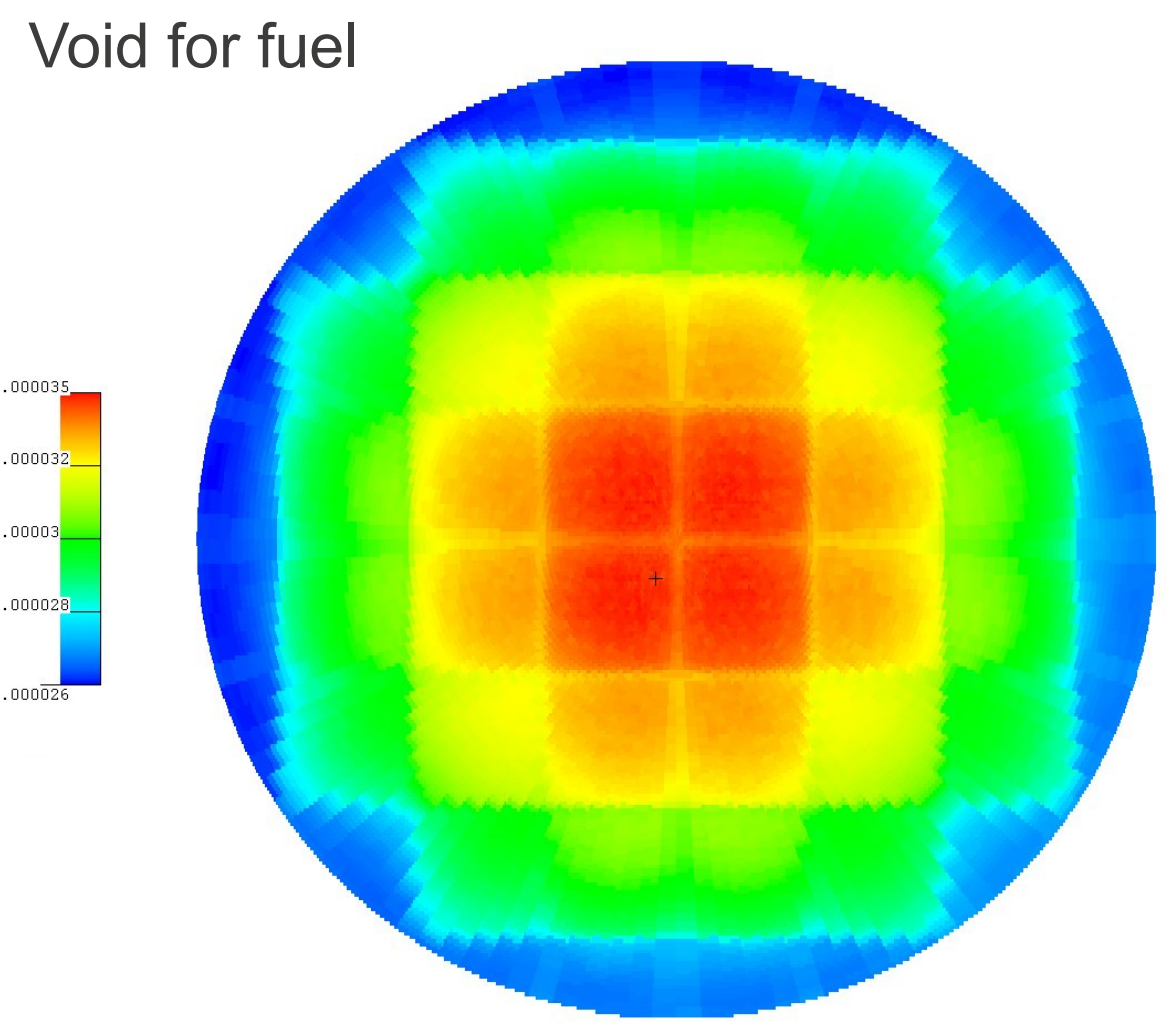




\section{The addition of inter-bundle structures results in approx. a $2 \%$ asymmetry in the flux}

- Ratio of upper left to lower right sections confirm that replacing the steel and neutron absorber results in symmetry

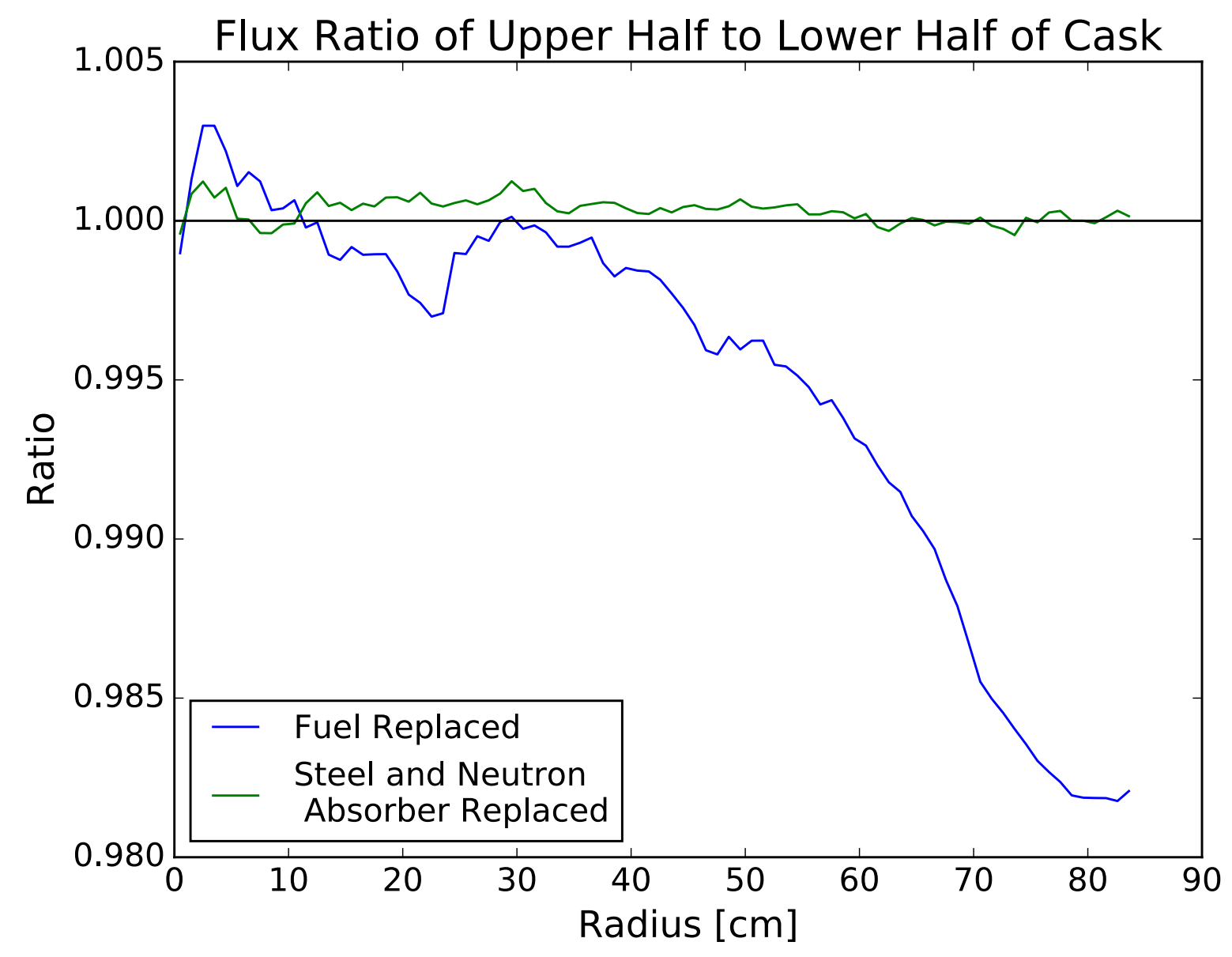




\section{Summary of Presentation}

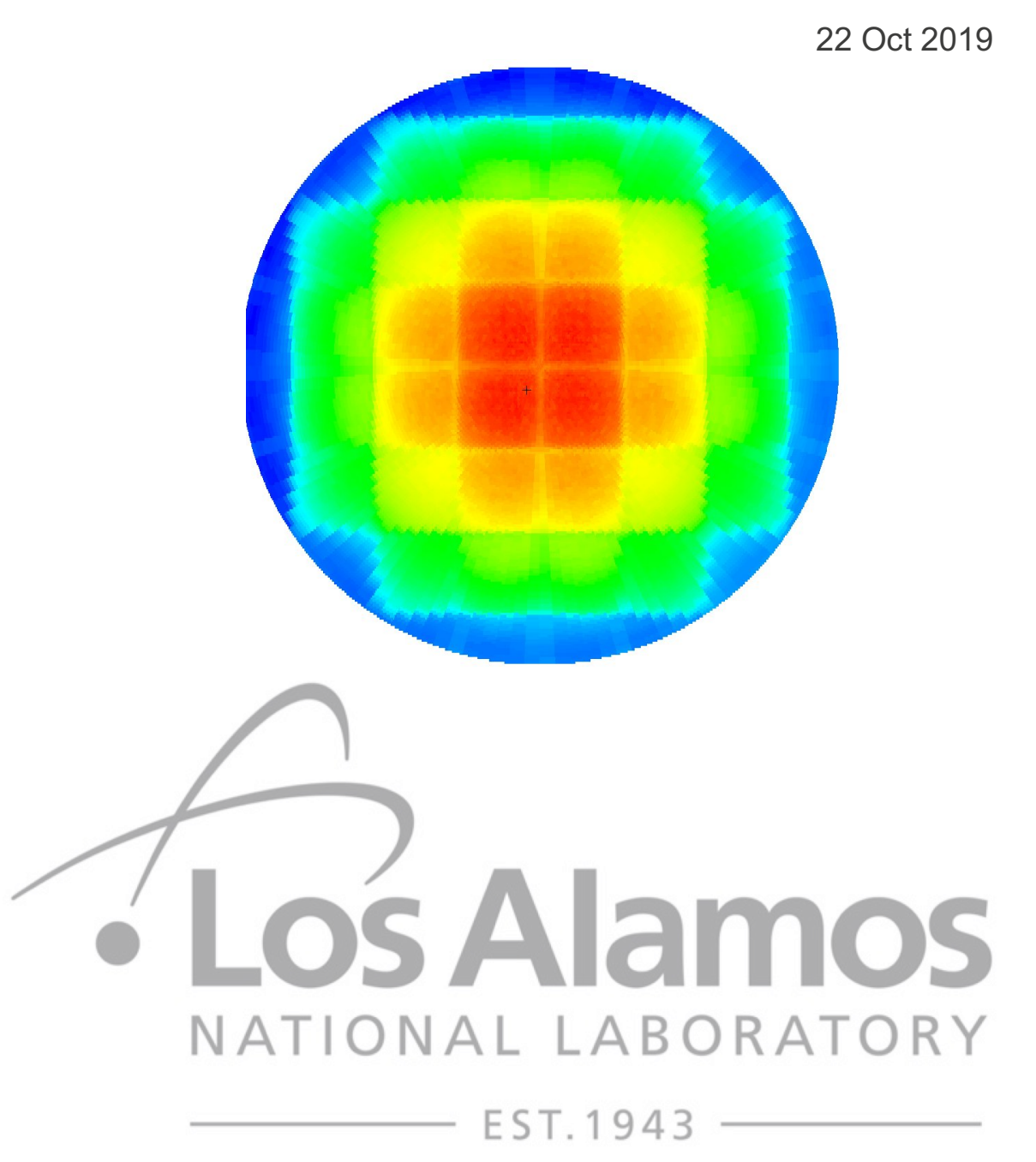

- Motivation

- Problem Description

- Feature Identification

- Discussion of Features

- Flat Flux Region Near Cask Centerline

- Periodic Depressions of Flux in Fuel Region

- Abrupt "Level-Off" Region

- Non-exponential Reduction in Overpack

- Asymmetric Flux

- Future Work 


\section{Analysis of simplified problems leads to a deeper understanding and enhanced evaluation of detailed problem}

- Modeling of simplified problems illuminates salient physics in detailed model and enhances evaluations

- Geometry at the single fuel rod level is less important than the material properties

- Further understanding of analytic models in concrete will also reveal dominant physics in the overpack

- By explaining the cause of these features, we gain confidence in the correctness of the detailed simulations

\section{Future work}

- Incorporate a multigroup discrete ordinance equation into 1-D array models

- Turn on/off physics in analytic models

- Finish $\mathrm{E}_{2} \mathrm{~S}_{4}$ calculation in concrete

- Investigate predictive capabilities

- Begin to sensitivity analysis in Dec/Jan 